\title{
Water Yield Variation due to Forestry Change in the Head-Water Area of Heihe River Basin, Northwest China
}

\author{
Feng Wu, ${ }^{1}$ Jinyan Zhan, ${ }^{1}$ Jiancheng Chen, ${ }^{2}$ Chao He, ${ }^{2}$ and Qian Zhang ${ }^{3,4}$ \\ ${ }^{1}$ State Key Laboratory of Water Environment Simulation, School of Environment, Beijing Normal University, Beijing 100875, China \\ ${ }^{2}$ School of Economics and Management, Beijing Forestry University, Beijing 100083, China \\ ${ }^{3}$ Institute of Geographic Science and Natural Resource Research, CAS, Beijing 100101, China \\ ${ }^{4}$ Center for Chinese Agricultural Policy, CAS, Beijing 100101, China
}

Correspondence should be addressed to Jinyan Zhan; zhanjy.bnu@gmail.com

Received 19 September 2014; Accepted 12 December 2014

Academic Editor: Hongbo Su

Copyright (C) 2015 Feng Wu et al. This is an open access article distributed under the Creative Commons Attribution License, which permits unrestricted use, distribution, and reproduction in any medium, provided the original work is properly cited.

Understanding the effects of forestation on the hydrological process is crucial to protecting water resources. In this study, the upstream Heihe River Basin is selected as the study area, which is the water source area of the whole basin. The grassland and forest are the main land use types, the proportion of which in the total land area is $21 \%$ and $50 \%$, respectively. Firstly, a scenario of forestation was designed with the actual land cover data in 1980. Then a scenario with simulated land cover data in 1980 was established, in which the forest area increases by $12 \%$. Thereafter a hydrological simulation was carried out with the actual and simulated land cover maps and the climate observation data during 1980-2010. The results suggested that the total water yield increased by $12.57 \mathrm{~mm}$ under the scenario with land use change during 1980-2010 compared with the simulation with the actual land cover in 1980 . However, the results also indicated that the surface runoff reduced by $22.17 \mathrm{~mm}$ during the same period, indicating the forest land has "sponge" effects on the water resource in the mountainous watershed. These results may provide important information that supports operational practices, such as forest regeneration programs and watershed restoration.

\section{Introduction}

Forestation has been encouraged worldwide for providing the ecosystem services. Understanding the effects of forestation is crucial to balance many ecosystem services provided by the forests (i.e., regulating seasonal flows, enhancing the availability of water resources, and ensuring water environment) $[1,2]$. The relationship between forests and water resources is a critical issue which must be accorded with high priority. A key challenge faced by the land, forest, and water managers is how to maximize the wide range of forest benefits without detriment to water resources and ecosystem functions. To address this challenge, there is an urgent need for a better understanding of the interactions between forests/trees and water, also for awareness raising and capacity building in forest hydrology, and for embedding this knowledge and the research findings in policies. The successful forestation programs which are implemented in China have improved the ecological as well as environmental conditions and have gained wide attention of many researchers and highlighted the relationship between forestation and water yields [3]. Forestation in upstream watershed is deemed as the most effective measure to enhance water availability for agriculture, industrial, and domestic uses [4]. However, some studies suggested that the hydrological benefits from forests in respect of increasing water yield and regulating dry season flow have been exaggerated [5-7]. Researchers even questioned the wisdom of having the forest as land cover to increase water yield in downstream regions [8]. Meanwhile, researchers also argued that the effects of forestation on runoff are not stationary [9]. A quantitative assessment of the hydrological effects of forestation, especially on the water yield, is therefore crucial for improving the forestation and water resource management to guarantee the sustainable forestry development within the arid or semiarid regions [10].

The hydrological effects of forestation of degraded land in the dry region have important implications for local and regional hydrological services, but such issues have 
been relatively less studied when compared to the issue of impacts of forest conversion [11]. Scientists from forestry and environmental sciences disciplines emphasized the significance of forests in regulating runoff and controlling soil erosion [1, 3, 12]. While scientists from other fields, for example, geography, climatology, and agriculture, argued that forests only have limited effects on water budgets and controlling flood [11, 13]. Overall, the relationship between forestation/reforestation and water yield is still a controversial issue. A central concept in the "traditional" view of the role of forests is the "sponge" effect of the tree roots, forest litter, and soil. It has been ever claimed that the tree roots soak up water during wet periods and release it slowly and evenly during the dry season to maintain water supplies [14]. The debate was endless because there were no convincing field data from research on forest hydrology, especially in China. Most literature suggested that the effects of forestation on annual flow are largely on the base flow, which is an important component of annual water yield for most forested watersheds. Some may conclude that forests increased base flow because the trees help to increase infiltration [9], while others may argue that forests used more water and thus reduced the base flow [2]. However, the hydrological consequences of forestation on degraded lands are not well studied in the forest hydrology research $[2,3]$.

Catchment parameters have great influence on responses of the water budget and runoff to forestation. The magnitude of effects of forestation on annual water yield varies as a function of vegetation, climate, soil, and management practices [8]. Hydrological models, for example, the soil and water assessment tool (SWAT), allow for simulating the hydrological effects of these catchment parameters, which can help to understand the effects of forestation on water yields in entire basin. The SWAT has been widely used in the water quantity and quality assessments at a wide range of scales and environmental conditions $[15,16]$. For example, applications of SWAT have been reported in rural [17, 18], more urbanized [19], and also coastal watersheds [20]. In addition, the SWAT has been successfully used to simulate the hydrological processes in the small upstream watershed of the Heihe River Basin [21, 22]. In this study, the SWAT model, which includes the components such as soil and vegetation, is used to analyze the effects of forestation on the water yield.

\section{Study Area}

The Heihe River Basin is located in a typical arid region of Northwest China that suffers from serious water scarcity. The annual precipitation is over $200 \mathrm{~mm}$ in regions above $2000 \mathrm{~m}$ in elevation and increases by $10.9 \sim 15.9 \mathrm{~mm}$ for every $100 \mathrm{~m}$ increase in elevation. The geography varied greatly in Heihe River Basin with the average altitude over $1200 \mathrm{~m}$ [21]. The main soil types in the watershed are alpine meadow soil, alpine steppe soil, frigid desert soil, gray cinnamonic soil, and gray-brown desert soil. The Heihe River Basin is divided into the upper, middle, and lower reaches, which differ significantly in the natural and socioeconomic characteristics. For example, the average annual precipitation in the upper, middle, and lower reaches is $200 \mathrm{~mm}$ to $600 \mathrm{~mm}$, less than
$200 \mathrm{~mm}$, and less than $50 \mathrm{~mm}$, respectively, while the annual evaporation ranges from $500 \mathrm{~mm}$ in the upper reach to over $3000 \mathrm{~mm}$ in the lower reach [23]. Besides, the ecosystem patterns range from alpine ecosystems on the south Qilian Mountain in the upstream to the oases at the Hexi Corridor in midstream basin and to the deserts in the north downstream basin $[24,25]$.

The Qilian Mountains with remarkably vertical landscape is the water source area, where the ecosystem patterns ranging from low to high altitude include dry shrubbery grassland, forest grassland, subalpine shrubbery meadow, alpine coldand-desert meadow, and alpine permafrost-snow-ice. Being an important regional headwater area, the upstream Heihe River Basin is selected as the study area, where the elevation ranges from $2000 \mathrm{~m}$ to about $5500 \mathrm{~m}$ (Figure 1). The area of the upstream is about $11145 \mathrm{~km}^{2}$. The dominant land use types are forestland and grassland, occupying nearly $21 \%$ and $50 \%$ of the total area, respectively. Picea crassifolia is the major species covering about $76.8 \%$ of the forest in upstream of Heihe River Basin.

\section{Data and Methodology}

SWAT is a semidistributed hydrological model based on geography and natural hydrological processes at the watershed scale. SWAT subdivides an entire watershed into subwatersheds connected with a river network and into smaller units that is called hydrological response units (HRUs). Each HRU represents a combination of land use, soil, and slope. HRUs are assumed to be nonspatially distributed with no interaction or dependency [26]. Major model components of SWAT include weather, hydrology, temperature and properties of soil, plant nutrients and growth, pesticides, bacteria, and land management [26]. The meteorological variables in SWAT include precipitation, temperature, wind speed, solar radiation, and relative humidity in daily or subdaily time steps. The model uses readily available inputs efficiently for computing the large watersheds and is capable of simulating long-term yields for determining impacts of land management practices [27]. SWAT allows a number of different physical processes to be simulated in a basin. The hydrological routine of SWAT actually and also potentially consists of discharge, snow melting, and evapotranspiration. SWAT has been successfully applied worldwide to solve many environmental issues in water quality and quantity studies $[28,29]$.

This study addressed the processes related to vegetation interception, infiltration, transpiration, and evaporation in the dry watersheds. Data used in this study are presented in Table 1 . The $30 \mathrm{~m}$ resolution Landsat TM images in 1980 were downloaded from the United States Geological Survey (USGS) website (http://earthexplorer.usgs.gov/) for mapping the land cover types in the upstream of the HRB in 1980. The collected images have already been georeferenced, and these images were then radiometrically corrected using the calibration utility for Landsat in ENVI 4.7 software package. The preprocessed images were subsequently clipped with the boundary of the study area. Supervised classification method was used to classify the land cover types in 1980. 
TABLE 1: Data used and sources information.

\begin{tabular}{|c|c|c|c|}
\hline Data type & Data source & Scale & Description \\
\hline DEM & $\begin{array}{l}\text { Shuttle radar topography mission } \\
\text { (SRTM) }\end{array}$ & $90 \mathrm{~m}$ & Elevation \\
\hline Soil & $\begin{array}{c}\text { Regional database } \\
\text { (http://westdc.westgis.ac.cn/) }\end{array}$ & $1: 1000000$ & $\begin{array}{c}\text { (Soil-Plant-Atmosphere-Water) } \\
\text { Field and Pond Hydrology model } \\
\text { was used to calculate some } \\
\text { parameters }\end{array}$ \\
\hline Weather & $\begin{array}{l}\text { China Meteorological } \\
\text { Administration (daily) }\end{array}$ & & 13 weather stations \\
\hline Hydrological observation & Hydrologic yearbook (daily) & & 4 stations \\
\hline River flow & $\begin{array}{l}\text { Data Center of Chinese Academy } \\
\text { of Science }\end{array}$ & $1: 250000$ & River network-diversion \\
\hline
\end{tabular}
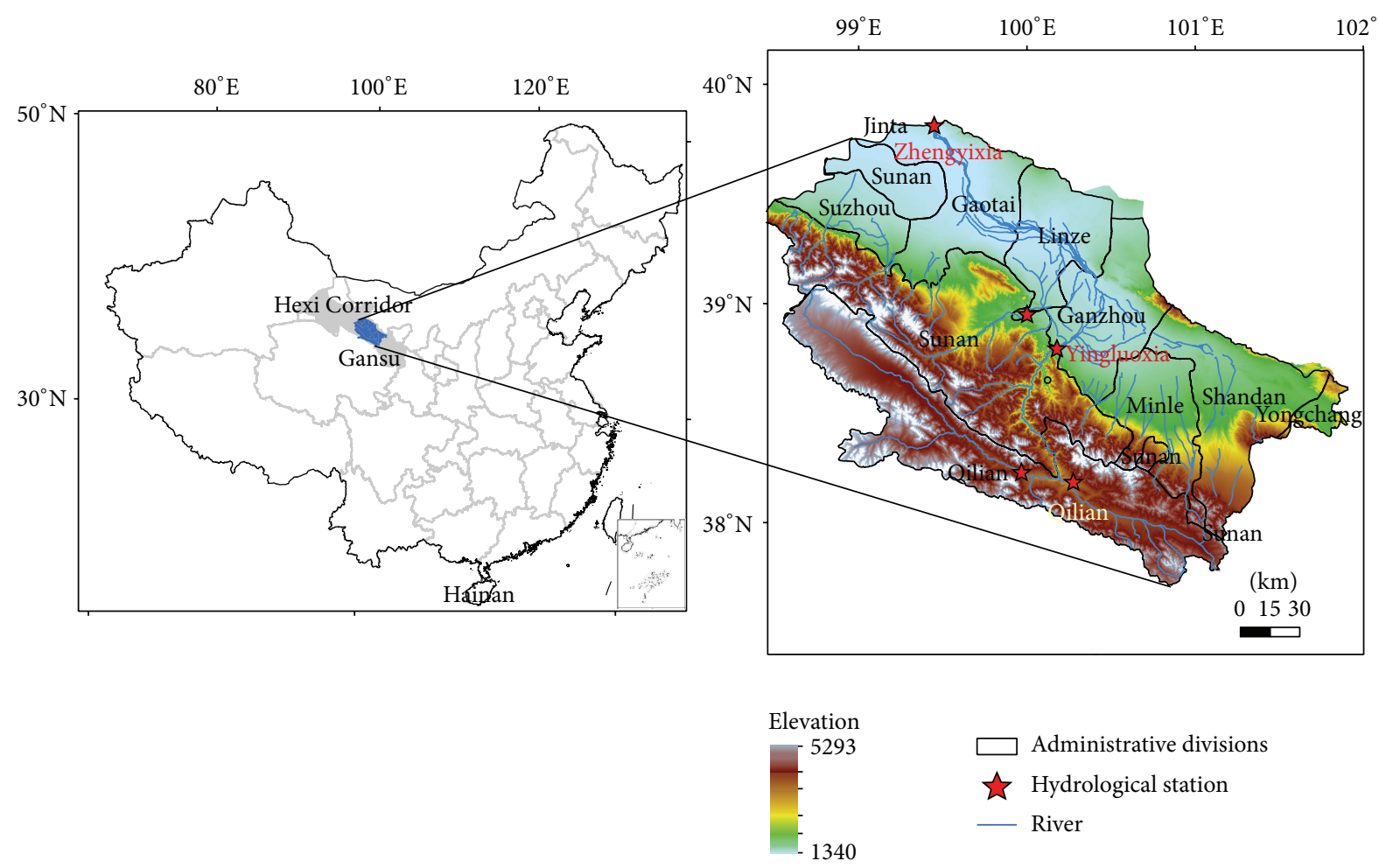

FIGURE 1: Location of administration region and hydrological station in the Heihe River Basin.

The Chinese Land Resource Classification System, from Data Center of Chinese Academy of Science, was used as the classification scheme to categorize the pixels of the image $[30,31]$. The classification system includes cultivated land, forestland, grassland, water, urban, and/or built-up area, and unused land. In this study, a baseline scenario of forestation was designed on the basis of the land cover in 1980, in which the forestry proportion is $21 \%$. Then a scenario was established with the simulated land cover data in 1980, in which the forest area increases by $12 \%$ compared to the actual land cover data in 1980. The regions with land use conversion are mainly located in the middle and west part of the study area (Figure 2). The precipitation data of Qilian weather station was also used to analyze the trend of precipitation. From 1980 to 2010, the precipitation showed a significantly upward trend, increasing at an average rate of $1.79 \mathrm{~mm} \cdot \mathrm{year}^{-1}$, and the annual average temperature significantly increased by $0.06^{\circ} \mathrm{C} \cdot$ year $^{-1}$ (Figure 3).

The hydrological routines within SWAT account for vegetation physical processes (e.g., infiltration, evaporation, plant uptake, lateral flows, and percolation) and ground water flows. As precipitation descends, it may be intercepted and held in the vegetation canopy or fall to the soil surface. Water on the soil surface will infiltrate into the soil profile or flow overland as runoff. The hydrological cycle that is simulated by SWAT is based on the water balance equation:

$$
\begin{gathered}
\mathrm{SW}_{t}=\mathrm{SW}_{0}+\sum_{t=1}^{t}\left(R_{\text {day }}(i)-\mathrm{Q}_{\text {surf }}(i)-E_{\text {sub }}(i)\right. \\
\left.-w_{\text {seep }}(i)-Q_{\mathrm{gw}}(i)\right),
\end{gathered}
$$




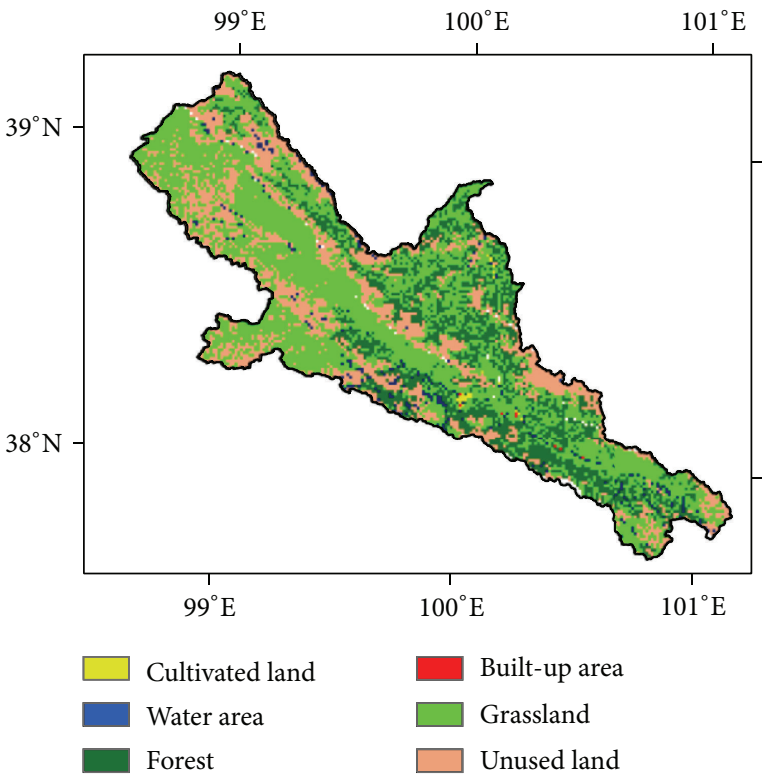

(a)

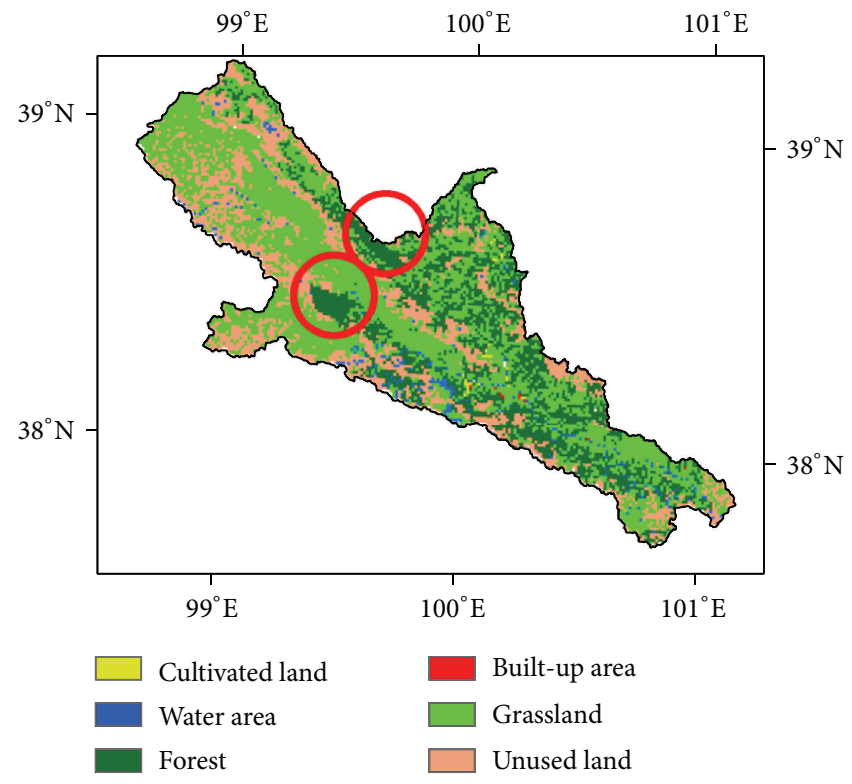

(b)

Figure 2: The land use map in the upstream of Heihe River Basin: (a) 1980; (b) scenario based simulated map.

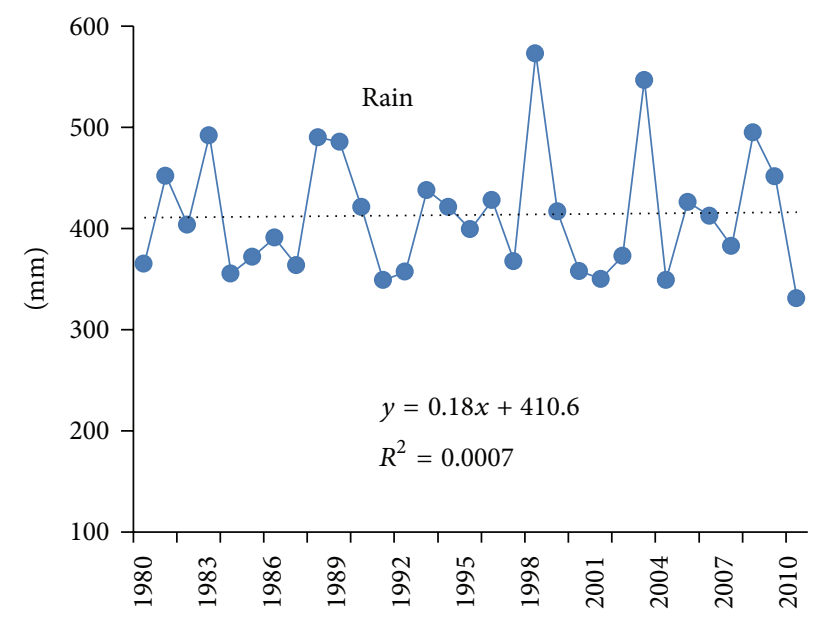

(a)

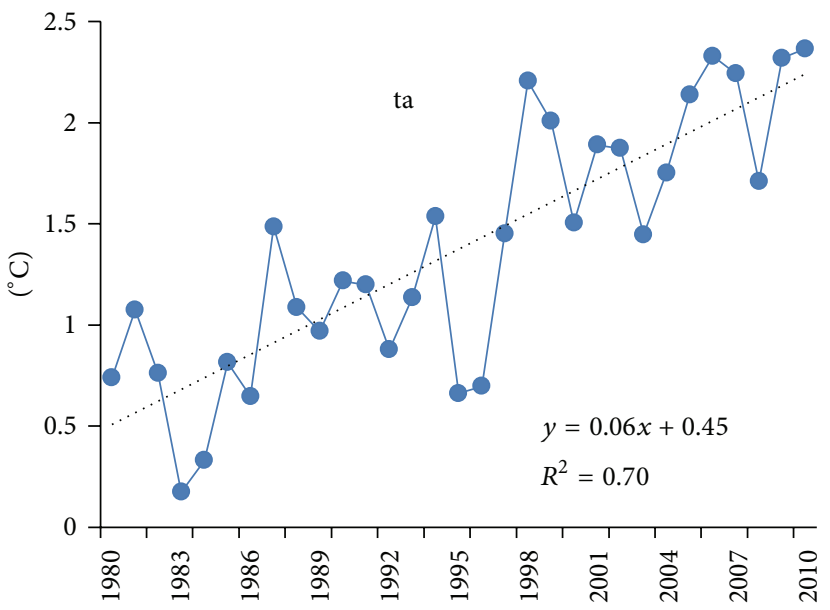

(b)

FIGURE 3: The change trend of precipitation and temperature at Qilan weather station during 1980-2010.

where $\mathrm{SW}_{t}$ is the final soil water content $\left(\mathrm{mm} \mathrm{H}_{2} \mathrm{O}\right), \mathrm{SW}_{0}$ is the initial soil water content on day $i\left(\mathrm{~mm} \mathrm{H}_{2} \mathrm{O}\right), t$ is the time (days), $R_{\text {day }}$ is the amount of precipitation on day $i$ $\left(\mathrm{mm} \mathrm{H}_{2} \mathrm{O}\right), Q_{\text {surf }}$ is the amount of surface runoff on day $i$ $\left(\mathrm{mm} \mathrm{H}_{2} \mathrm{O}\right), E_{\text {sub }}$ is the amount of evapotranspiration on day $i$ $\left(\mathrm{mm} \mathrm{H}_{2} \mathrm{O}\right), w_{\text {seep }}$ is the amount of water entering the vadose zone from the soil profile on day $i\left(\mathrm{~mm} \mathrm{H}_{2} \mathrm{O}\right)$, and $Q_{\mathrm{gw}}$ is the amount of return flow on day $i\left(\mathrm{~mm} \mathrm{H}_{2} \mathrm{O}\right)$.

The role of forest vegetation in influencing hydrological processes can be well analyzed with the SWAT model. The canopy storage value and the leaf area index are used in the SWAT model to compute the maximum storage at any time in the growth cycle of the land cover. SWAT utilizes a single plant growth model to simulate all types of land cover. This model is able to differentiate between annual and perennial plants. When the evaporation is computed, water is firstly removed from canopy storage. Plant transpiration is simulated as a linear function of potential evapotranspiration and leaf area index. SWAT allows the maximum amount of water held in canopy storage to vary from day to day as a function of leaf area index:

$$
\operatorname{can}_{\mathrm{day}}=\operatorname{can}_{\mathrm{mx}} \times \frac{\mathrm{LAI}}{\mathrm{LAI}_{\mathrm{mx}}},
$$

where $\mathrm{can}_{\text {day }}$ is the amount of water that can be trapped in canopy on a given day $\left(\mathrm{mm} \mathrm{H}_{2} \mathrm{O}\right), \mathrm{can}_{\mathrm{mx}}$ is the maximum amount of water that can be trapped in canopy on a given day $\left(\mathrm{mm} \mathrm{H}_{2} \mathrm{O}\right)$, and LAI is the leaf area index of the 
canopy. For the other potential evapotranspiration methods, transpiration is calculated as follows:

$$
\begin{aligned}
& E_{t}=\frac{E_{0}^{\prime} \times \mathrm{LAI}}{3.0} \quad 0 \leq \mathrm{LAI} \leq 3.0, \\
& E_{t}=E_{0}^{\prime} \quad \mathrm{LAI}>3.0,
\end{aligned}
$$

where $E_{t}$ is the maximum transpiration on a given day $\left(\mathrm{mm} \mathrm{H}_{2} \mathrm{O}\right), E_{0}^{\prime}$ is the potential evapotranspiration adjusted for evaporation of free water in the canopy $\left(\mathrm{mm} \mathrm{H}_{2} \mathrm{O}\right)$, and LAI is the leaf area index.

The Penman-Monteith equation combines components that account for energy needed to sustain evaporation and the strength required to remove the water vapor and aerodynamic and surface resistance terms. Consider

$$
\lambda E=\frac{\Delta \times\left(H_{\mathrm{net}}-G\right)+\rho_{\mathrm{air}} \times C_{P} \times\left[e_{z}^{0}-e_{z}\right] / r_{a}}{\Delta+\gamma \times\left(1+\gamma_{c} / \gamma_{a}\right)},
$$

where $\lambda E$ is the latent heat flux density $\left(\mathrm{MJ} \cdot \mathrm{m}^{-2} \cdot \mathrm{d}^{-1}\right), E$ is the depth rate evaporation $\left(\mathrm{mm} \cdot \mathrm{d}^{-1}\right), \Delta$ refers to the slop of the saturation vapor pressure-temperature curve, de/dT $\left(\mathrm{kpa} \cdot{ }^{\circ} \mathrm{C}^{-1}\right), H_{\text {net }}$ is the net radiation $\left(\mathrm{MJ} \cdot \mathrm{m}^{-2} \mathrm{~d}^{-1}\right), G$ is the heat flux density to the ground, $\rho_{\text {air }}$ is the air density, $C_{P}$ is the specific heat at constant pressure $\left(\mathrm{MJ} \cdot \mathrm{kg}^{-1} \cdot{ }^{\circ} \mathrm{C}^{-1}\right), e_{z}^{0}$ is the saturation vapor pressure of air at height $z, e_{z}$ is water vapor pressure at height $z$ (kpa), $\gamma$ is the psychometric constant $\left(\mathrm{kpa} \cdot{ }^{\circ} \mathrm{C}^{-1}\right), \gamma_{c}$ is the plant canopy resistance $\left(\mathrm{s} \cdot \mathrm{m}^{-1}\right)$, and $\gamma_{a}$ is the diffusion resistance of the air layer $\left(\mathrm{s} \cdot \mathrm{m}^{-1}\right)$. Studies of the canopy resistance have shown that the canopy resistance for a well-watered reference crop can be estimated by dividing the minimum surface resistance for a single leaf by one-half of the canopy leaf area index:

$$
\gamma_{c}=\frac{\gamma_{e}}{0.5 \times \mathrm{LAI}},
$$

where $\gamma_{c}$ is the canopy resistance $(\mathrm{s} / \mathrm{m})$ and $\gamma_{e}$ is the minimum effective stomatal resistance of a single leaf $(\mathrm{s} / \mathrm{m})$.

A standard hydrological model performance criterion has been proposed. In this study, Nash-Sutcliffe coefficient $\left(E_{\mathrm{ns}}\right)$ and coefficient of determination $\left(R^{2}\right)$ were used as model performance indices. Model performance was high when $E_{\mathrm{ns}}>0.5$ and $R^{2}>0.8$. Here, $E_{\mathrm{ns}}$ is the relationship strength between observed value $Q_{o, i}$ and simulated value $Q_{m, i}$ at time t. $E_{\mathrm{ns}}$ lies between $-\infty$ and +1 , and in this study $E_{\mathrm{ns}}$ should be closer to +1 . The square of Pearson's product moment correlation, $R^{2}$, represents the proportions of total variance of measured data that can be explained by simulated data, and the model performance is higher when $R^{2}$ is closer to 1 . Consider

$$
\begin{aligned}
E_{\mathrm{ns}} & =1-\frac{\sum_{i=1}^{n}\left(Q_{o, i}-Q_{m, i}\right)^{2}}{\sum_{i=1}^{n}\left(Q_{o, i}-\bar{Q}_{o}\right)^{2}}, \\
R^{2} & =\frac{\left[\sum_{i=1}^{n}\left(Q_{o, i}-\bar{Q}_{o}\right)\left(Q_{m, i}-\bar{Q}_{m}\right)\right]^{2}}{\sum_{i=1}^{n}\left(Q_{o, i}-\bar{Q}_{o}\right)^{2} \sum_{i=1}^{n}\left(Q_{m, i}-\bar{Q}_{m}\right)^{2}},
\end{aligned}
$$

where $E_{\mathrm{ns}}$ is the Nash-Sutcliffe coefficient, $Q_{o, i}$ is the observed runoff in $i$ years, $Q_{m, i}$ the simulated runoff in $i$ years, and $n$ is the length of the time series. The closer the $E_{\mathrm{ns}}$ and $R^{2}$ is to 1 , the more accurate the model prediction is.

\section{Results}

We simulated the effect of forestation on water yield using the SWAT model which couples the vegetation and physical processes. The SWAT model was calibrated according to the daily observation data records during 1980-1990 from Yingluoxia Hydrological Station, which is an outlet of the upstream area and the simulation results were validated with the daily observation records during 1990-2000. Some parameters were updated after the calibration. Both calibration of the model and validation of the simulation results show that the SWAT model performed well in simulating the hydrological process in the upstream area of the Heihe River Basin. The coefficients in (6) were determined with eligible evaluation of calibration and validation. The results showed that $R^{2}$ reached 0.72 and 0.70 for the calibration as well as the validation periods, respectively. With regard to the model performance, the $E_{\mathrm{ns}}$ values for the calibration and validation periods ( 0.80 and 0.79 , resp.) correspond to "good" and "good," respectively (Figure 4). The two coefficients of validation were lower than the calibration period, the reason for which is the use of the land use map in 1980. Moreover, by comparing the simulation results with the observation records from Yingluoxia Hydrological Station, we cannot reject the significance of the parameters of the SWAT model, indicating the model is suited for simulating the water balance in the upstream area of the Heihe River Basin.

The intervals of the most sensitive parameters were identified and the most appropriate values are eventually shown in Table 2. The temperature lapse rate (TLAPS) is the most sensitive parameter, and it is directly related to the melting process of snow and glacier. Snow melting occurs mostly from March to June in a subwatershed. The snow melting factor on June 21 was parameterized to be SMFMX, which is the maximum melting rate; any increase of SMFMX drives rapid snow melting. The snow temperature lag factor TIMP is also linked with SMFMX because it is based on the previous situation. Along with TIMP surface water lag time, SURLAG plays an important role in influencing the model performance as a melted snow routing process is related to the geology of the watershed, where the melted water mainly flows to the surface runoff covering the impervious rock formations. SMTMP is sensitive since it indicates the starting and ending of melting of snow and glacier, the availability of snow melting on a specific day, and the model-simulated streamflow, especially their peak values, are significantly influenced by the variation of SMTMP. Some parameters were updated after the calibration, and both calibration of the model and validation of the simulation results show that the model performed well in simulating the runoff variation due to glacier melting and climate change in upstream Heihe River Basin.

Streamflow production may be related to the differences in climatic pattern, meteorological conditions, species 


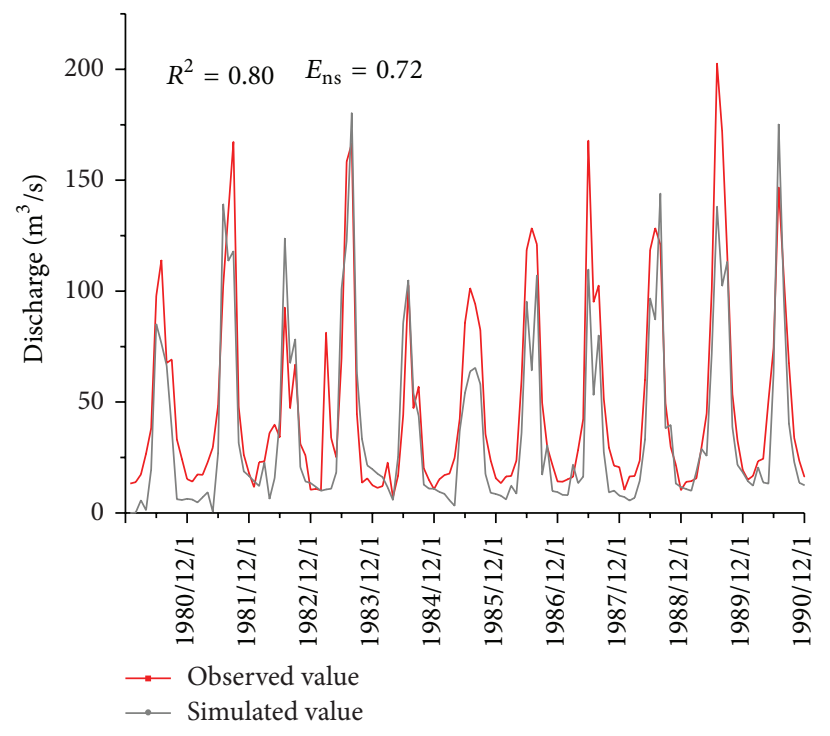

(a)

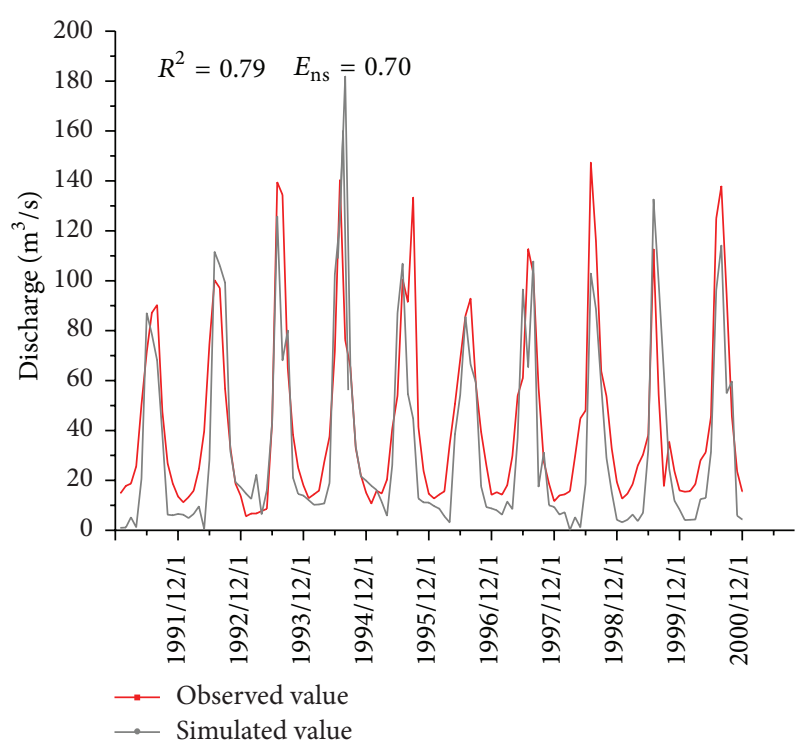

(b)

FIGURE 4: The calibration and validation of monthly discharge at the Yingluoxia hydrological station, observed versus simulated using the SWAT.

TABLE 2: Ranges and values of the most sensitive parameters in SWAT model.

\begin{tabular}{|c|c|c|c|}
\hline Parameters & Descriptions & Ranges & Values \\
\hline $\mathrm{CN}_{2}$ & SCS curve number & $-20 \% \sim 20 \%$ & $+6.32 \%$ \\
\hline Sol_k & Saturated hydrological conductivity & $-20 \%-20 \%$ & $+11.56 \%$ \\
\hline Escno & Evaporation compensation factor & $0 \sim 1.0$ & 0.83 \\
\hline SFTMP & Snowfall temperature & $-2.0 \sim 2.0^{\circ} \mathrm{C}$ & $0.9^{\circ} \mathrm{C}$ \\
\hline Sol_z & Depth from soil surface to bottom of layer & $-20 \%-20 \%$ & $+3.65 \%$ \\
\hline Sol_Awc & Available soil water content & $-20 \%-20 \%$ & $-0.35 \%$ \\
\hline GWQMN & Threshold depth of water in the shallow aquifer required for return flow to occur & $0-500 \mathrm{~mm}$ & 306.5 \\
\hline ALPHA_BF & Base flow alpha factor & $0.00 \sim 1.00$ & 0.07 \\
\hline
\end{tabular}

composition, canopy structure, and morphological characteristics of tree leaves, branches, and bark. Canopy rainfall interception varied from 14.7 to $31.8 \%$ of total rainfall, depending upon stand characteristics of different land cover type. Forest canopy interception was also affected by rainfall characteristics, which generally decreases with the rainfall amount and intensity. Evapotranspiration (ET), including physical evaporation and biological transpiration, is a significant component of forest water budgets, ranging in 80$90 \%$ of the total rainfall in the region. As expected, the actual amount of ET raised due to the increase of temperature and rainfall, whereas the amount of ET is relatively low in the mountainous watershed. ET from a forest is generally higher than that from pasture or bare land. However, ET is about $600 \mathrm{~mm}$ in the forest cover in the upstream area of the Heihe River Basin, which is far lower than that in those regions covered by grassland or unused land. The ET/PET ratio of native grasslands declined as the fastest, followed by pine woodlands, shrub lands, alfalfa, and croplands. Pine woodland's low ET/PET ratios were mainly caused by its higher runoff due to soil compaction resulting from soil desiccation.
Previous studies have shown that the effect of forestation on water yield may differ among regions due to the difference in the topography, soil properties, and climate conditions [32]. The simulation results in this study suggest that the monthly average water yield has generally increased, with an increment of $15.7 \mathrm{~mm}$ during 1980-2010 (Figure 5). The increase of water yield mainly happened in summer, while the decrease of water yield mainly occurred in winter. This may be due to the water conservation function of the forests. The study area is located in the mountain area with an altitude of approximately $3000 \mathrm{~m}$, where the annual rainfall is about $600 \mathrm{~mm}$ and the slope is generally very high, and the forests intercept a large proportion of rainfall. The forest has a more powerful conservation function compared to the grassland, and it is more difficult to generate runoff in the forest than in the grassland. The results of the two simulation experiments show that the monthly average runoff decreased by $22.12 \mathrm{~mm}$ when the forest area increased during 1980-2010. In addition, the simulation results show that the interflow declined dramatically, the monthly average value of which decreased by approximately $500 \mathrm{~mm}$ during $1980-$ 2010. This may be due to the difference in the moisture 


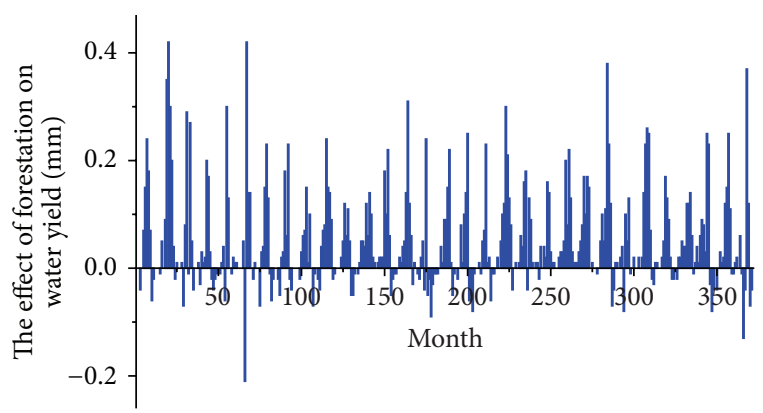

FIGURE 5: The difference of water yield between forestation scenario and baseline during 1980-2010.

infiltration between forests and grasslands. The surface roots of forests can absorb more surface moisture and keep the shallow soil moist. By comparison, the surface roots of grasslands are generally very shallow, which can promote the infiltration of rainfall into the soil.

The results of this study may not coincide with that of some research about the relationship between forestation and water yield. A recent review also shows that reforestation can cause decreased water yield [9]. However, the belief is based on the assumption of a constant relationship between precipitation and ET; that is, a reduced ET can logically lead to a gain of water yield. However, if this assumption is not true or if the relationship between precipitation and ET varies over time and space, the simple logic may be not tenable. Besides, forestation practices may cause the decrease of annual water yield due to the increase of ET. For any statistical tests, streamflow data must be first naturalized to account for other water uses. Moreover, the majority of the statistical studies are experiments at the plot scale, whereas there are few watershed-scale studies. Therefore, using ET information to infer water yield may not always be correct.

It is difficult to accurately simulate the hydrological processes because they are influenced by a myriad of biophysical factors. The results of this study suggest that the effect of forestation on water yield differs in different areas, and the forestation has positive effects on the water yield in the mountainous area. Several influential studies have also demonstrated the uncertainty and variability of forestation on potential hydrological responses across China due to the large differences in climate and soil conditions [33]. At the same time, most studies have focused on understanding whether forests are important in influencing water protection and soil erosion, and almost none of them have aimed at determining what percentage of forested land in a watershed or a landscape must be protected in order to minimize negative impacts on water resources. This question is important and must be answered in order to provide reference information for designing and implementing sustainable forest management practices.

\section{Conclusion}

The study concludes that there was a significant positive relationship between forestation and water yield in the upstream area of the Heihe River Basin during 1980-2010. The annual water yield increased by $1.2 \mathrm{~mm}$ when the forest cover increased by $1 \%$. The result also suggested that the surface runoff have reduced $1.8 \mathrm{~mm}$ with every $1 \%$ increase in the forest cover. Besides, although forestation generally reduces runoff, the effects of forestation on the water yield may vary greatly in different regions due to the differences in topography, soil, and climatic conditions. The results of this study are different from that of some previous studies, but all studies have demonstrated that forests play an important, positive role in reducing surface runoff and peak streamflow. In spite of inconsistent results from those studies about forestation and the hydrological processes, the simulation experiment continues to allow us to build a solid foundation in understanding the interactions between forests and hydrological processes. It can be beneficial to improving the sustainable forest management to apply the hydrological models in regions where there are sufficient data since this approach allows us to evaluate the impacts of different forest management scenarios on hydrology within a short time.

\section{Conflict of Interests}

The authors declare that there is no conflict of interests regarding the publication of this paper.

\section{Acknowledgments}

This research was financially supported by the National Natural Science Funds of China for Distinguished Young Scholar (Grant no. 71225005), the major research plan of the National Natural Science Foundation of China (Grant no. 91325302), and the Key Project in the National Science \& Technology Pillar Program of China (no. 2013BAC03B00).

\section{References}

[1] L. Chen, J. Wang, W. Wei, B. Fu, and D. Wu, "Effects of landscape restoration on soil water storage and water use in the Loess Plateau Region, China," Forest Ecology and Management, vol. 259, no. 7, pp. 1291-1298, 2010.

[2] Z.-J. Wang, J.-Y. Jiao, Y. Su, and Y. Chen, "The efficiency of large-scale afforestation with fish-scale pits for revegetation and soil erosion control in the steppe zone on the hill-gully Loess Plateau," CATENA, vol. 115, pp. 159-167, 2014.

[3] H. Bi, B. Liu, J. Wu, L. Yun, Z. Chen, and Z. Cui, "Effects of precipitation and landuse on runoff during the past 50 years in a typical watershed in Loess Plateau, China," International Journal of Sediment Research, vol. 24, no. 3, pp. 352-364, 2009.

[4] S. Singh and A. Mishra, "Spatiotemporal analysis of the effects of forest covers on water yield in the Western Ghats of peninsular India," Journal of Hydrology, vol. 446-447, pp. 24-34, 2012.

[5] S. W. Trimble, F. H. Weirich, and B. L. Hoag, "Reforestation and the reduction of water yield on the southern Piedmont since circa 1940," Water Resources Research, vol. 23, no. 3, pp. 425-437, 1987.

[6] A. K. Sikka, J. S. Samra, V. N. Sharda, P. Samraj, and V. Lakshmanan, "Low flow and high flow responses to converting natural grassland into bluegum (Eucalyptus globulus) in Nilgiris 
watersheds of South India," Journal of Hydrology, vol. 270, no. 12, pp. 12-26, 2003.

[7] M. Robinson, "30 years of forest hydrology changes at Coalburn: water balance and extreme flows," Hydrology and Earth System Sciences, vol. 2, no. 2-3, pp. 233-238, 1998.

[8] I. R. Calder, "Assessing the water use of short vegetation and forests: development of the hydrological land use change (HYLUC) model," Water Resources Research, vol. 39, no. 11, p. 1318, 2003.

[9] D. F. Scott, L. A. Bruijnzeel, R. A. Vertessy, and I. R. Calder, "Hydrology: impacts of forest plantations on streamflow," in Encyclopedia of Forest Sciences, J. Burley, Ed., pp. 367-377, Elsevier, Oxford, UK, 2004.

[10] Y. Wang, P. Yu, K.-H. Feger et al., "Annual runoff and evapotranspiration of forestlands and non-forestlands in selected basins of the Loess Plateau of China," Ecohydrology, vol. 4, no. 2, pp. 277-287, 2011.

[11] P. Yu, Y. Wang, A. Du et al., “The effect of site conditions on flow after forestation in a dryland region of China," Agricultural and Forest Meteorology, vol. 178-179, pp. 66-74, 2013.

[12] L. Deng, Z.-P. Shangguan, and R. Li, "Effects of the grain-forgreen program on soil erosion in China," International Journal of Sediment Research, vol. 27, no. 1, pp. 120-127, 2012.

[13] J. Krishnaswamy, M. Bonell, B. Venkatesh et al., "The groundwater recharge response and hydrologic services of tropical humid forest ecosystems to use and reforestation: support for the 'infiltration-evapotranspiration trade-off hypothesis"' Journal of Hydrology, vol. 498, pp. 191-209, 2013.

[14] N. Myers, "Tropical moist forests: over-exploited and underutilized?" Forest Ecology and Management, vol. 6, no. 1, pp. 5979, 1983.

[15] C. R. Castillo, İ. Güneralp, and B. Güneralp, "Influence of changes in developed land and precipitation on hydrology of a coastal Texas watershed," Applied Geography, vol. 47, pp. 154167, 2014.

[16] M. Faramarzi, K. C. Abbaspour, R. Schulin, and H. Yang, "Modelling blue and green water resources availability in Iran," Hydrological Processes, vol. 23, no. 3, pp. 486-501, 2009.

[17] K. Kirsch, A. Kirsch, and J. Arnold, "Predicting sediment and phosphorus loads in the Rock River basin using SWAT," Transactions of the ASAE, vol. 45, no. 6, pp. 1757-1769, 2002.

[18] A. Saleh, J. G. Arnold, P. W. Gassman et al., "Application of SWAT for the upper North Bosque River watershed," Transactions of the American Society of Agricultural Engineers, vol. 43, no. 5, pp. 1077-1087, 2000.

[19] J. Franczyk and H. Chang, "The effects of climate change and urbanization on the runoff of the Rock Creek basin in the Portland metropolitan area, Oregon, USA," Hydrological Processes, vol. 23, no. 6, pp. 805-815, 2009.

[20] T. Lee, R. Srinivasan, J. Moon, and N. Omani, "Estimation of fresh water inflow to bays from gaged and ungaged watersheds," Applied Engineering in Agriculture, vol. 27, no. 6, pp. 917-923, 2011.

[21] Q. Huang and W. Zhang, "Improvement and application of GIS-based distributed SWAT hydrological modeling on high altitude, cold, semi-arid catchment of Heihe River Basin, China," Journal of Nanjing Forestry University (Natural Sciences Edition), vol. 28, pp. 22-26, 2004.

[22] Z. Li, Runoff simulation in the upper reaches of Heihe River Basin and uncertainty anakysis in hydrological modeling [Ph.D. thesis], Beijing Normal University, Beijing, China, 2009.
[23] Q. Feng, G. D. Cheng, and K. N. Endo, "Towards sustainable development of the environmentally degraded River Heihe basin, China," Hydrological Sciences Journal, vol. 46, no. 5, pp. 647-658, 2001.

[24] Z. Li, Z. Xu, Q. Shao, and J. Yang, "Parameter estimation and uncertainty analysis of SWAT model in upper reaches of the Heihe river basin," Hydrological Processes, vol. 23, no. 19, pp. 2744-2753, 2009.

[25] N. L. Wang, S. B. Zhang, J. Q. He, J. C. Pu, X. B. Wu, and X. Jiang, "Tracing the major source area of the mountainous runoff generation of the Heihe River in northwest China using stable isotope technique," Chinese Science Bulletin, vol. 54, no. 16, pp. 2751-2757, 2009.

[26] S. Neitsch, J. Arnold, J. Kiniry, and J. R. Williams, "Soil and water assessment tool: theoretical documentation, version 2005," 2005.

[27] J. G. Arnold, R. Srinivasan, R. S. Muttiah, and P. M. Allen, “Continental scale simulation of the hydrologic balance," Journal of the American Water Resources Association, vol. 35, no. 5, pp. 1037-1051, 1999.

[28] S. M. Pradhanang, A. Anandhi, R. Mukundan et al., "Application of SWAT model to assess snowpack development and streamflow in the Cannonsville watershed, New York, USA," Hydrological Processes, vol. 25, no. 21, pp. 3268-3277, 2011.

[29] E. Varanou, E. Gkouvatsou, E. Baltas, and M. Mimikou, "Quantity and quality integrated catchment modeling under climate change with use of soil and water assessment tool model," Journal of Hydrologic Engineering, vol. 7, no. 3, pp. 228-244, 2002.

[30] X. Deng, H. Su, and J. Zhan, "Integration of multiple data sources to simulate the dynamics of land systems," Sensors, vol. 8, no. 2, pp. 620-634, 2008.

[31] X. Deng, J. Liu, Y. Lin, and C. Shi, "A framework for the land use change dynamics model compatible with RCMs," Advances in Meteorology, vol. 2013, Article ID 658941, 7 pages, 2013.

[32] X. Deng, Q. Jiang, J. Zhan, S. He, and Y. Lin, "Simulation on the dynamics of forest area changes in Northeast China," Journal of Geographical Sciences, vol. 20, no. 4, pp. 495-509, 2010.

[33] X. Wei, S. Liu, G. Zhou, and C. Wang, "Hydrological processes in major types of Chinese forest," Hydrological Processes, vol. 19, no. 1, pp. 63-75, 2005. 

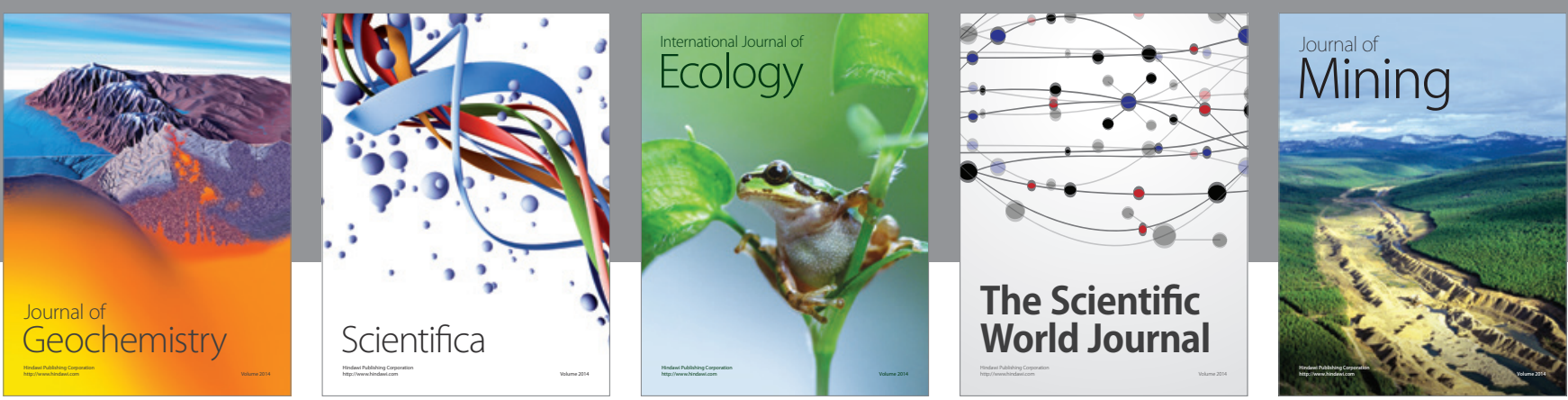

The Scientific World Journal
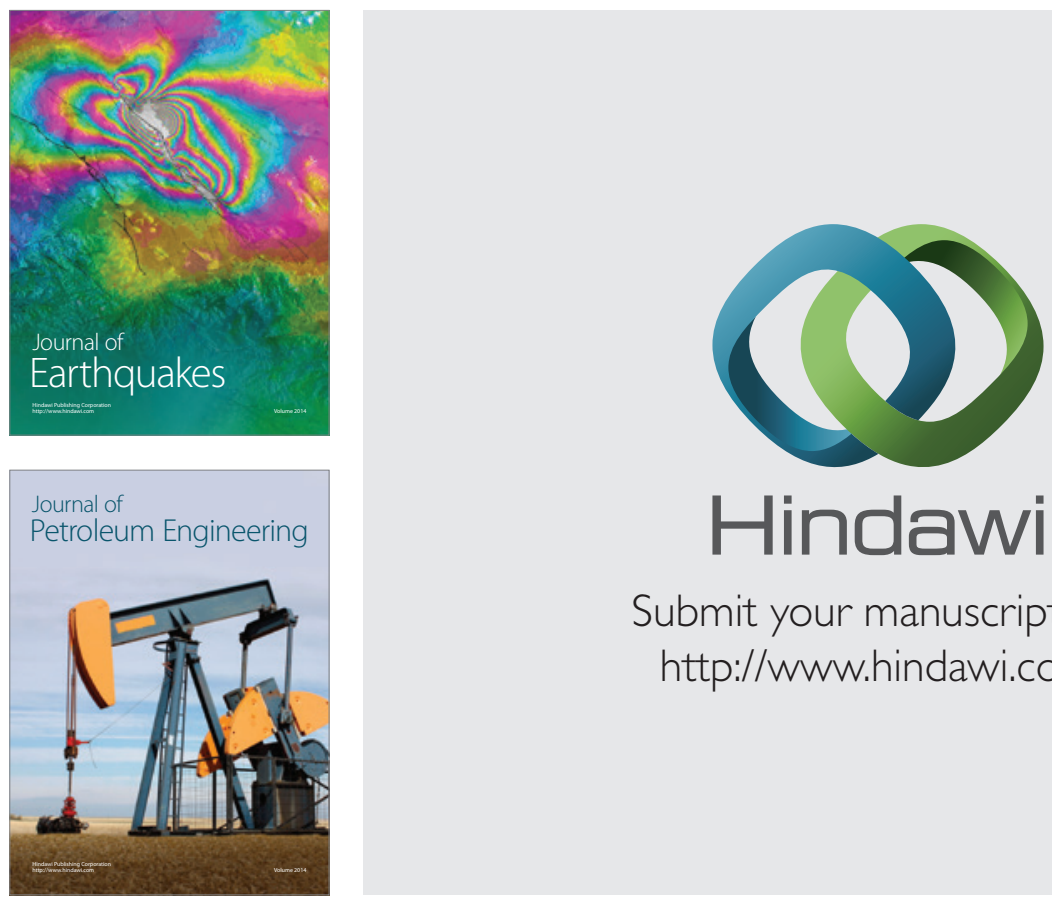

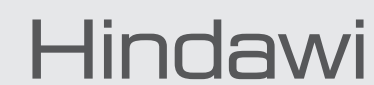

Submit your manuscripts at

http://www.hindawi.com
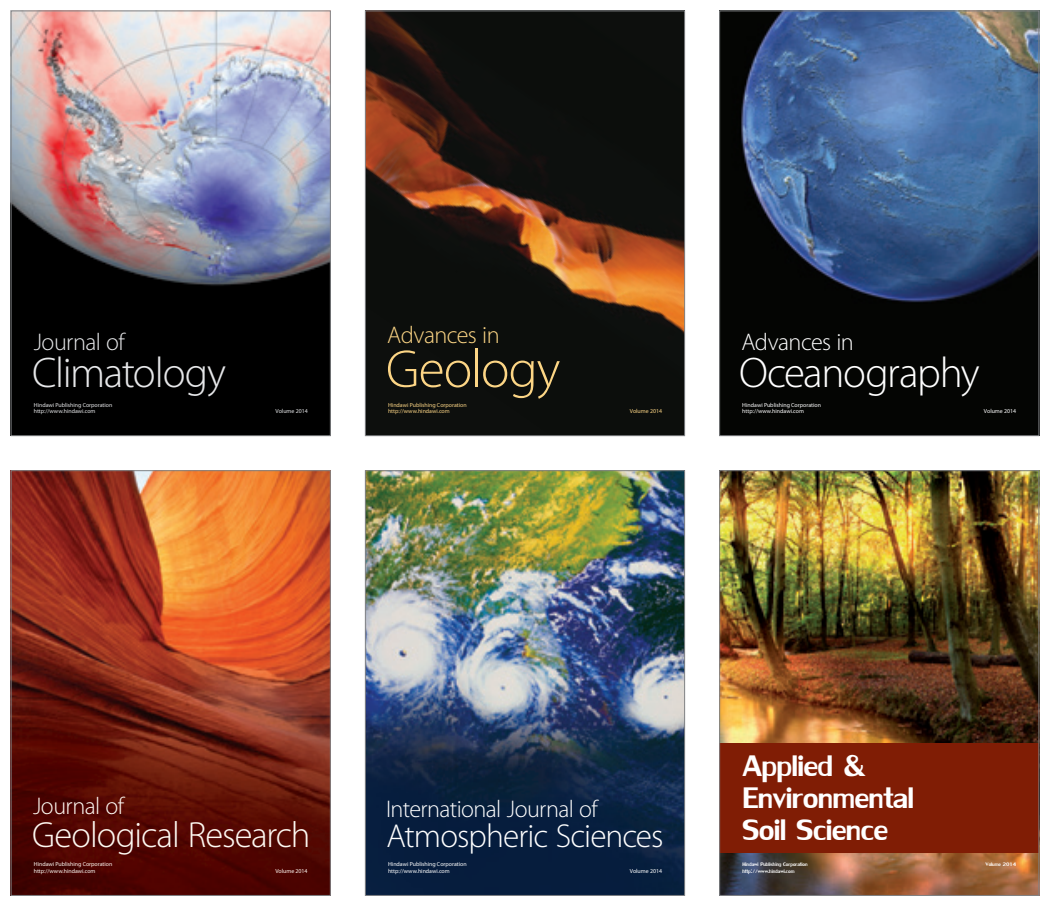
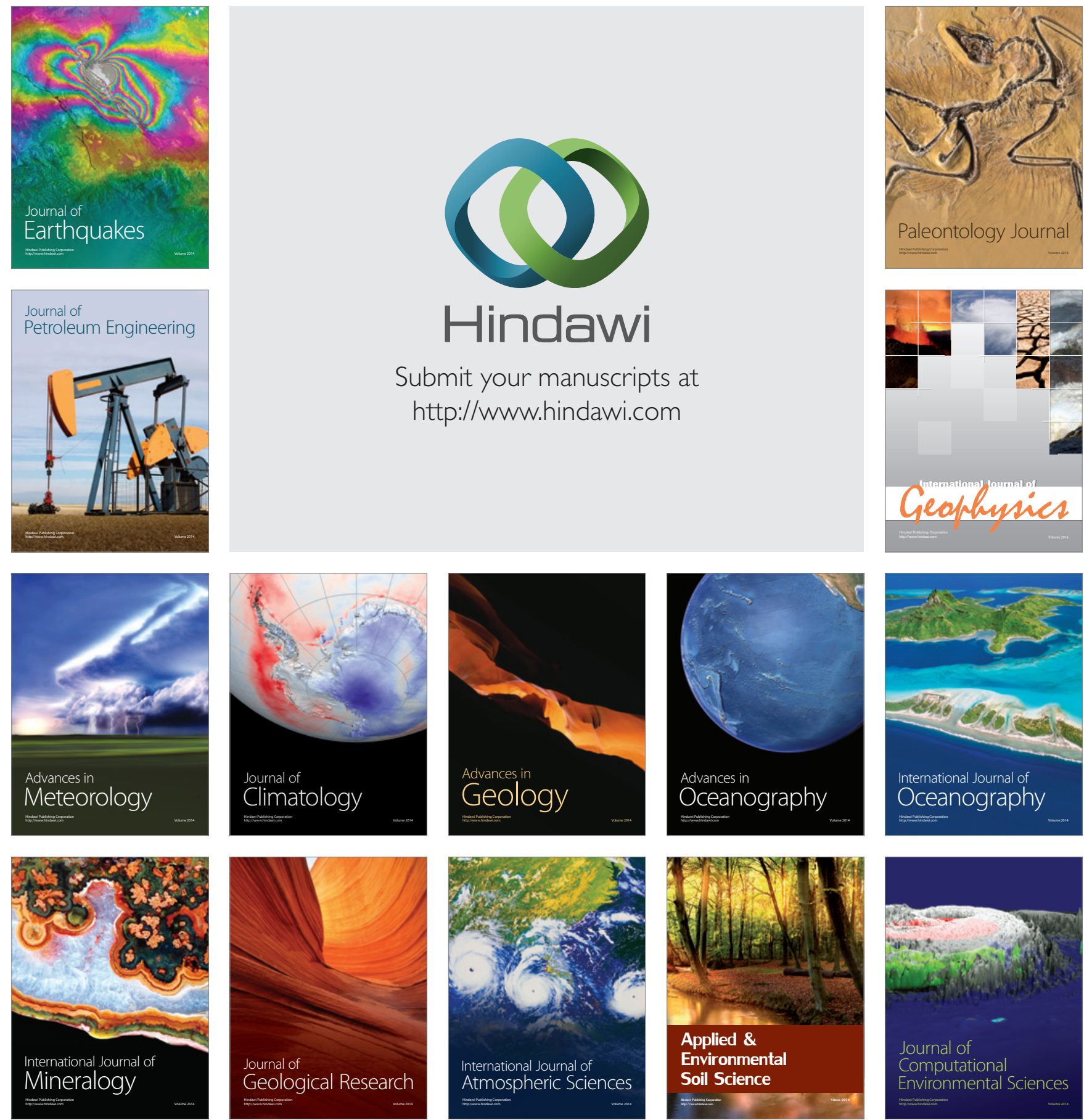